\title{
Resíduos Sólidos e a Solução de Problemas Locais em Bairros Periféricos: o Caso do Programa Lixo Que Vale de Umuarama - PR
}

\author{
Solid Waste and the Solution of Local Problems in Peripheral Districts: a Case Study \\ of Valuable Trash Program in Umuarama - PR
}

Residuos Sólidos y la Solución de Problemas Locales en Barrios Perifericos: el Caso
del Programa Basura que Vale en Umuarama - PR

Angela Danielle Kuhn ${ }^{1}$

Fábio de Oliveira Neves ${ }^{2}$

\begin{abstract}
RESUMO: Os resíduos sólidos têm sido interpretados como problema socioespacial, já que têm o potencial de degradação ambiental e ameaça à saúde pública. No entanto, há uma percepção alternativa destes enquanto solução, pois materiais reaproveitados podem ser respostas a problemas sociais, econômicos e ambientais. Gerir os resíduos sólidos de modo criativo e reinseri-los no ciclo de produção é um desafio. Em Umuarama-PR desenvolve-se o programa Lixo que Vale, com o objetivo de estimular a separação entre resíduos domésticos recicláveis e orgânicos e de resolver problemas ambientais e sociais em bairros periféricos: Jabuticabeiras, Sete Alqueires, Industrial, Arco Íris, Viveiros e Alto da Glória. O objetivo deste artigo é analisá-lo no período de sua existência (20102018), considerando os diferentes agentes sociais envolvidos e as estratégias do poder público na resolução de problemas locais. Para isso, discutiu-se a problemática do lixo enquanto fenômeno socioespacial, como problema ou solução para questões locais. Em seguida, realizou-se levantamento de dados sobre a gestão municipal dos resíduos sólidos. Posteriormente, realizaram-se entrevistas semiestruturadas visando caracterizar o programa, levantar opiniões e compreender suas fragilidades. Os resultados mostram que o programa consegue atingir distintas áreas (ambiental, alimentar, emprego e renda) e distribui seus benefícios entre diferentes agentes (população, agricultores e catadores). Algumas fragilidades ameaçam sua permanência: mudanças na gestão municipal e dependência de recursos públicos.
\end{abstract}

PALAVRAS-CHAVE: Gestão de resíduos sólidos. Bairros periféricos. Problemas socioambientais.

ABSTRACT: Solid waste has been interpreted as a socio-spatial problem due its environmental degradation potential and for its threat to public health. However, there is an alternative perception: waste as solution. When discarded materials are reused, they can be the answer to social, economic and environmental problems. Managing solid waste in a creative way and reinserting it into the cycle of production is a challenge. In the city of Umuarama-PR, the Valuable Trash Program has been

\footnotetext{
${ }^{1}$ UTFPR, Campus Toledo. Endereço: Rua Cristo Rei, 19, Campus da UTFPR, 85902-490, Toledo, Paraná, email: angelakuhn@utfpr.edu.br.

${ }^{2}$ Programa de Pós-graduação em Geografia da Unioeste, Campus de Mal. Cândido Rondon, Endereço: Rua Pernambuco, 1777, Campus da Unioeste, 85960-000, Mal. Cândido Rondon, Paraná, e-mail: fabio.neves@unioeste.br.
} 
developed to stimulate the separation between recyclable and organic garbage and to solve environmental and social problems in peripheral areas: Jabuticabeiras, Sete Alqueires, Industrial, Arco Íris, Viveiros and Alto da Glória neighborhoods. The objective of this paper is to analyze the program since it was created (2010-2018), considering different social agents involved and the strategies of the public administration in solving local issues. It was debated about waste as socio-spatial phenomenon: as a problem or as solution. It was raised data about the solid waste management. Semi-structured interviews were made to characterize the program, to collect opinions and to understand its weaknesses. The results show that the program achieves distinct fields (environment, food, employment and income) and distributes its benefits to different agents (inhabitants, farmers, waste pickers). Some weaknesses threaten its permanence: changes in local public administration and dependence on public resources.

KEYWORDS: Solid waste management. Peripheral areas. Socio-environmental problems.

RESUMEN: Los residuos sólidos han sido interpretados como problema socioespacial, ya que tienen el potencial de degradación ambiental y amenazan la salud pública. Sin embargo, hay una percepción alternativa, como solución, ya que los materiales reaprovechados pueden responder a problemas sociales, económicos y ambientales. Gestionar los residuos de modo creativo y su reinserción en el ciclo de producción es un desafío. En la ciudad de Umuarama, se desarrolla el Programa Basura que Vale, con la intención de estimular la separación entre residuos reciclables y orgánicos y resolver problemas ambientales y sociales en barrios periféricos: Jabuticabeiras, Sete Alqueires, Industrial, Arco Íris, Viveiros y Alto da Glória. El objetivo del artículo es analizar las actividades del Programa desde que fue creado (2010-2018), considerando diferentes agentes sociales implicados y las estrategias del poder público para resolver los problemas locales. Se discute la basura como fenómeno socioespacial. Se realiza el levantamiento de datos sobre la gestión municipal de los residuos. Se realizaron entrevistas con el fin de caracterizar el Programa, recoger opiniones y comprender sus debilidades. Los resultados muestran que se puede alcanzar distintas áreas (ambiental, alimentación, empleo y renta) y los beneficios se distribuyen entre diferentes agentes (populación, agricultores y cartoneros). Hay algunas debilidades que amenazan su continuidad como cambios en la gestión municipal y la dependencia de recursos públicos.

PALABRAS-CLAVE: Gestión de residuos sólidos. Barrios periféricos. Problemas socioambientales.

\section{INTRODUÇÃO}

A gestão integrada dos resíduos sólidos é formada por um conjunto de ações que compreendem aspectos variados como o ambiental, o econômico, o social e o espacial. É um meio pelo qual se busca a resolução de problemas e, para isso, evidencia a necessidade do envolvimento de diferentes agentes sociais. O gerenciamento dos resíduos sólidos vai muito além de remover materiais descartados para longe da visão das pessoas. Está voltado para uma série de etapas que abrangem: a separação dos resíduos nas residências; a coleta seletiva; o transporte; e a destinação ambientalmente adequada.

Os resíduos são comumente interpretados como problema socioespacial, já que têm o potencial de degradação ambiental e de ameaça à saúde pública. No entanto, chama-se a atenção para uma percepção alternativa dos resíduos enquanto solução, pois materiais 
descartados quando reaproveitados podem ser a resposta a problemas econômicos e ambientais locais. Portanto, gerir os resíduos sólidos de modo criativo e reinseri-los no ciclo produção, consumo e descarte é um desafio lançado à sociedade.

O município de Umuarama, localizado na mesorregião Noroeste do Paraná, desenvolve o Programa Lixo que Vale (PLV) como meio de promover a separação de materiais recicláveis, combater a degradação ambiental e auxiliar populações pobres que se encontram em situação de insegurança alimentar. Nesse sentido, verifica-se a tentativa de resolver diferentes problemas locais por meio de um mesmo programa.

Considerando o exposto, têm-se as seguintes indagações: Em que consiste e como está organizado o Programa Lixo que Vale? Quem participa, quais são os benefícios e quem é beneficiado pelo programa? Quais são os seus resultados? Quais são suas fragilidades?

Os questionamentos nos levaram a definir como objetivo deste artigo: analisar o PLV enquanto ação integrada para a solução de problemas locais em bairros periféricos selecionados, ou seja, os bairros de Jabuticabeiras, Sete Alqueires, Industrial, Arco Íris, Viveiros e Alto da Glória. Propomos adicionalmente os seguintes objetivos específicos: compreender a criação e o funcionamento do PLV; conhecer a função dos diferentes agentes participantes do programa; reconhecer as percepções dos atores envolvidos com o PLV, buscando seus pontos positivos, mas também levantando suas fragilidades.

A metodologia aplicada envolve aspectos qualitativos e quantitativos. As informações e dados obtidos se deram por meio do levantamento de referencial teórico sobre os resíduos como fenômeno socioespacial, com o intuito de pôr em evidência uma dupla representação sobre eles (problema ou solução); da consulta ao Sistema Nacional de Informações sobre Saneamento - SNIS, com o objetivo de organizar e demonstrar aspectos quantitativos da gestão municipal de resíduos sólidos em Umuarama e o impacto do PLV junto aos agentes envolvidos nos bairros participantes do programa; da realização de oito entrevistas semiestruturadas a agentes institucionais de Umuarama-PR e catadores, visando descrever o histórico de formação do programa, as dificuldades, as transformações no decorrer de seu funcionamento e a opinião dos entrevistados sobre o mesmo; e atividade em campo para observação direta das instalações (acompanhadas de técnico para descrição de processos e atividades; e com registro fotográfico do que foi observado), das diferentes etapas da gestão dos resíduos e do funcionamento do programa.

\section{O LIXO COMO FENÔMENO SOCIOESPACIAL: PROBLEMA OU SOLUÇÃO?}

O homem, no seu processo de vivência e desenvolvimento, cria e recria o espaço, pois é nele que se estabelece. A sociedade e o espaço não podem se dissociar já que estão 
intimamente ligados em um movimento de produção e reprodução social/espacial (CARLOS, 2007).

As relações homem/meio são desenvolvidas no espaço sob parâmetros territoriais que definem normas, meios e recursos, de modo a contemplar uma área delimitada. Assim, "Os sujeitos se interagem com a natureza exterior ao homem. Na relação espaço versus território, também há reciprocidade, pois se entrelaçam, superpõem-se e estão em unidade" (SAQUET, 2013, p. 158).

Produzir e reproduzir a sociedade e o espaço sob o território requer ações que podem resultar na produção de lixo/resíduos sólidos. Sendo assim, o lixo torna-se um fenômeno socioespacial, torna-se uma consequência da inter-relação da sociedade com o meio em que vive. O lixo como fenômeno apresenta múltiplas facetas, isso significa que pode ser interpretado de várias formas a depender do ângulo que se pretende analisar. A Lei Federal 12.305/10, no artigo $3^{\circ}$., XVI, define resíduos sólidos como:

[...] material, substância, objeto ou bem descartado resultante de atividades humanas em sociedade, a cuja destinação final se procede, se propõe proceder ou se está obrigado a proceder, nos estados sólido ou semissólido, bem como gases contidos em recipientes e líquidos cujas particularidades tornem inviável o seu lançamento na rede pública de esgotos ou em corpos d'água, ou exijam para isso soluções técnicas ou economicamente inviáveis em face da melhor tecnologia disponível (BRASIL, 2010).

No entanto, analisar os resíduos exige reflexão para além da letra da lei, pois por meio do lixo é possível interpretar contextos históricos variados e buscar solução para problemas, quando utilizado de forma estratégica em diferentes situações. O lixo é uma classificação variável em momentos distintos e, portanto, visto como recurso ou valorizado quando situações econômicas díspares assim o requerem (NEVES, 2013).

O lixo como fenômeno socioespacial é analisado como resultado das ações humanas que se desenvolvem no espaço e sofrem influência de aspectos territoriais; pode ser avaliado em contextos diferentes; e está relacionado à sociedade de consumo e descarte que se potencializa no sistema econômico hegemônico vigente, o capitalismo.

Böck (2003, p. 10) ressalta que: "[...] foi a partir do capitalismo que transformações mais radicais começaram a surgir, conduzindo a desequilíbrios ambientais e sociais mais intensos". Sustentar o processo produção, consumo e descarte requer estratégias, demanda de recursos naturais e produção de resíduos. O meio ambiente sofre com a sua deterioração gradual, seja no momento da fabricação de mercadorias ou na disposição final do material descartado, após consumido, enquanto lixo, especialmente quando estamos diante de um sistema de produção linear. Nesse sistema, o material descartado não é 
reaproveitado. Isso ocasiona extração, poluição e contaminação de recursos naturais, pois o sistema de produção capitalista necessita de matéria-prima para produzir.

\title{
PRODUÇÃo dE RESídUOS X RECURSOS NATURAIS: OS RESídUOS COMO PROBLEMA
}

Os resíduos são vistos ao longo da história como problema, uma vez que podem poluir rios, solos e ar, recursos fundamentais para a manutenção e qualidade da vida humana.

\begin{abstract}
O primeiro problema desse lixo é o fato de constituir ambiente favorável ao desenvolvimento de insetos [...] e ratos. A famosa peste bubônica, que na Idade Média causou a morte de grande parte das populações da Europa e da Ásia, deveu-se, principalmente, ao hábito que se tinha na época de lançar o lixo às ruas. Isso permitia a proliferação incontrolável de ratos, os quais passaram a invadir as casas, para onde levavam suas pulgas, que são os vetores da peste (BRANCO, 1999, p. 84).
\end{abstract}

A forma com que os resíduos eram descartados, sem local específico para disposição e tratamento, tornava propício o desenvolvimento de patologias e mostrava-se como ameaça à saúde das pessoas. Era necessário que medidas fossem tomadas a fim de interferir nos danos que estavam sendo causados pela falta de tratamento do lixo.

Ainda na Idade Média, surgem normas que proíbem a disposição nas ruas do lixo produzido, o que estimula a construção de fossas que são esvaziadas periodicamente. No entanto, esse meio de descarte do lixo e das águas servidas também causava problemas à saúde pública, uma vez que poluía fontes d'água (EIGENHEER, 2009). Não se tardou a perceber que essa era uma forma de camuflar um problema tornando-o ainda maior.

Só a partir do século XX há a denominação dos resíduos sólidos como a conhecemos atualmente. Antes, a expressão mais comum era "imundícies", a qual se referia a todo o tipo de material descartado seja líquido, pastoso ou sólido, pois não havia, necessariamente, separação entre eles (EIGENHEER, 2003).

Dar destinação aos resíduos sólidos de modo a preservar recursos naturais foi um desafio das sociedades passadas e continua a ser das sociedades presentes. A produção de resíduos é inevitável e é intensificada por meio do avanço de técnicas e de tecnologias. Exemplo disso é dado por Calderoni (2003, p. 225):

No mundo, o consumo de plástico vem crescendo a taxas muito elevadas. De um total de apenas 6 milhões de toneladas consumidas em 1960, nos primórdios da introdução deste produto, passou-se para 27 milhões de $t$ em 1970; 53 milhões de t em 1980; 93 milhões de t em 1990; chegando-se a 110 milhões de t em 1994. 
Os dados apontados referem-se, apenas, ao consumo do plástico, no entanto vários outros materiais fazem parte do processo produção, consumo e descarte, como papel, alumínio e vidro. A mercadoria produzida, após ser consumida, é descartada. Os resíduos descartados geram desconforto à sociedade e prejudicam a saúde dos indivíduos quando tornados rejeitos e quando não são dispostos em aterros sanitários.

Além do problema da produção de resíduos e dificuldade em dar destinação que não polua o meio ambiente, a intensa produção de mercadorias é responsável pela extração cada vez maior de recursos naturais, o que causa preocupações tendo em vista a sua característica finita. "O consumismo [...] é causa de [...] grave problema: o esgotamento dos recursos naturais não-renováveis, isto é, aqueles que, uma vez consumidos, não podem ser novamente repostos, como, por exemplo, o petróleo e os minérios em geral (BRANCO, 1999, p. 44).

Recursos naturais, como ar, solo e água são elementos indispensáveis para a vida no planeta Terra. Mesmo com toda a tecnologia desenvolvida e dominada pelo homem, não é possível a vida sem a apropriação de recursos naturais. Ainda, com potencial de criação de materiais sintéticos, como plástico, isopor e materiais de limpeza, o homem não tem domínio sobre a criação artificial dos elementos que são essenciais a sua sobrevivência.

O fato é que o lixo ou resíduo produzido tem a capacidade de poluir e contaminar os vários recursos naturais indispensáveis à vida do homem. O ar torna-se cada vez mais poluído devido ao montante de gazes emitido por indústrias e automóveis. O solo é contaminado quando utilizado para disposição de resíduos sem tratamento, pois os materiais quando entram em decomposição (com evidência os orgânicos) produzem chorume. O chorume infiltra no solo atingindo o lençol freático, o qual contamina poços artesianos e rios (BRANCO, 1999).

Quando não recebe tratamento, o lixo produzido pode tornar-se problema concomitantemente ambiental e social, visto que gera incômodo, podendo contaminar recursos naturais e ser provedor de agentes patológicos.

O que fazer com o lixo provindo do descarte daquilo que não mais é útil, seja por ter perdido a validade e não mais funcionar, seja por ter se tornado obsoleto diante de modelos ou cores novas lançadas aos produtos? O que fazer com os milhões de toneladas de lixo dispostos no meio ambiente de modo a poluir os recursos naturais sem os quais o homem não sobrevive?

É preciso adesão a meios que visem o reaproveitamento de materiais descartados, como a reutilização e a reciclagem. É importante a criação de estratégias que valorizem o lixo e desse modo o torne recurso para a solução de problemas locais. 
A responsabilidade da separação entre material orgânico e reciclável nas residências é do cidadão. É dever da administração pública a coleta diferenciada, que deve variar conforme o material (reciclável ou não) e a disposição final adequada. É indispensável que haja uma cooperativa ou empresa que receba o material reciclável coletado e dê o tratamento necessário para sua comercialização, como a triagem dos materiais, conforme sua composição, e prensagem. É necessário que as fábricas priorizem, no seu processo de produção, materiais reciclados ou recicláveis (BRASIL, 2010).

\section{NOVAS ESTRATÉGIAS E ENVOLVIMENTO DE AGENTES SOCIAIS: RESÍDUOS COMO SOLUÇÃO}

Ao verificar os diferentes impactos negativos gerados pela gestão inadequada e ineficiente dos resíduos sólidos, nos confrontamos com a seguinte indagação: o que fazer diante desse cenário? O cenário é de inconstâncias e características variadas, as quais precisam ser consideradas no desafio do ser humano de buscar soluções aos problemas por ele desenvolvidos e que o atinjam direta ou indiretamente.

As inconstâncias destacam-se do fato de que o espaço é dinâmico, sendo assim, está em constante movimento e transformação. A transformação do espaço é evidenciada pelas ações do homem que modifica o meio ambiente na intenção de suprir suas necessidades. Essa problemática abrange diferentes agentes, como: empresas, indústrias, comércios, cooperativas, sindicatos, ONG's, cidadãos; e aspectos que influenciam na construção das sociedades, como: econômicos, sociais, políticos, culturais.

A busca por soluções aos problemas ambientais e sociais, ocasionados por meio da produção de resíduos, carece, segundo Alió (2008), da prevenção em um primeiro momento e da reciclagem, posteriormente. Na mesma linha de pensamento, Calderoni (2003, p. 26) aponta que: "[...] só resta buscar, por um lado, a minimização da geração de resíduos, e, por outro, a reciclagem desses resíduos, já que sua produção é inevitável [...]".

A prevenção está relacionada ao desenvolvimento de técnicas que reduzam o montante de resíduos, entre os quais podemos citar aqueles oriundos do processo de produção de mercadorias (gerados por fábricas e indústrias) e os originados após o consumo de mercadorias, com $\mathrm{o}$ ato do descarte (feito pelos indivíduos). Essas técnicas devem focar na diminuição do desperdício de materiais por parte das indústrias e em ações que sensibilizem os indivíduos quanto ao consumo e descarte.

O consumo responsável está ligado à diminuição ou redução do consumo. Isso significa não ir de encontro à moda, às tendências, e não se deixar levar pelos estímulos midiáticos. As pessoas possuem a livre escolha no momento do consumo, mas as mídias têm a capacidade de induzir a determinadas ações e à criação de "falsas necessidades". O 
descarte apropriado se refere à separação dos resíduos pelos indivíduos, no intuito de contribuir para a coleta seletiva e aproveitamento dos materiais descartados com a reutilização e a reciclagem.

Assim, a sensibilização dos indivíduos quanto ao consumo e descarte de mercadorias (consumir menos e descartar de forma adequada) pode ser estimulada por políticas públicas por meio de normas ou programas. Todavia, se as administrações públicas agirem em direção à redução do consumo pode haver atrito com empresas, indústrias e comerciantes, uma vez que essa tática é contraditória ao sistema que os movimenta. Sensibilizar as pessoas à redução do consumo significa frear a produção de mercadorias já que a demanda pelo consumo será menor. O resultado, do ponto de vista econômico, é menor geração de lucro, o que confronta a lógica capitalista de produção.

[...] razones que obstaculizan el avance de la prevención en origen estriba en hecho que las campañas de educación ambiental destinadas a promover la responsabilidad y la reducción de determinados productos implican directamente al centro del sistema económico, que tiene precisamente en el consumo desenfrenado y poco consciente una de las bases de su crecimiento (ALIÓ, 2008, s/p).

Dessa forma, os termos "prevenção" e "minimização da geração de resíduos" denotam meios que tanto as fábricas e indústrias podem buscar com estratégias que visem minimizar o montante de resíduos oriundos da produção de mercadorias; quanto os indivíduos podem reduzir o consumo (o que indica redução de descartados) pela prática de um pensamento menos influenciado por impulsos midiáticos.

Para a manutenção do sistema capitalista, o acúmulo de capital é fundamental. O capital se dá por meio da mais valia, a qual obtém recursos financeiros. O lucro é obtido por meio da produção e comercialização de serviços e mercadorias. A produção de mercadorias se dá por meio da extração de recursos naturais, pois são a matéria-prima. $O$ desenvolvimento de políticas públicas ambientais acaba por frear o andamento da lógica capitalista (na qual o consumo é estimulado e com ele a consequência é a produção de resíduos) indo de encontro ao movimento do sistema. Isso pode significar a redução dos lucros de governos, empresas, indústrias e comerciantes. Dessa forma, há maior dificuldade em pôr em prática ações que previnam a produção de resíduos.

A reciclagem requer a transformação do material descartado em novo material, assim, o resíduo é submetido a técnicas que alteram suas propriedades físicas, físico-químicas ou biológicas (BRASIL, 2010). Geralmente, essa forma de reaproveitamento de materiais é desenvolvida por indústrias especializadas.

Além da reciclagem, citada por Alió (2008), outra forma de valorização dos resíduos é a reutilização, que é o ato de reaproveitar um material sem ter que mudar o seu estado 
biológico, físico ou físico-químico (BRASIL, 2010). O material é esterilizado, quando necessário, e reutilizado para uma finalidade, para a qual foi criado ou não. Essa ação pode ser feita tanto pela indústria (acondicionamento de alimentos) como por pessoas (artesanatos).

A prevenção, a reciclagem e a reutilização exigem mudanças nas políticas de meio ambiente e se mostram como "[...] un proceso lento, fragmentado y difícil, y que se concreta en el espacio de maneira desigual, inclusive entre pueblos y ciudades de un mismo entorno geográfico" (ALIÓ, 2008, s/p). O processo é lento e ocorre de maneira desigual, justamente, por sofrer influências das inconstâncias e características variadas do espaço no processo de construção das relações socioespaciais.

A gestão de resíduos vai além do simples descarte e disposição longe dos olhos dos indivíduos (esse processo era comum e justificável em momentos históricos nos quais não se tinha o domínio de técnicas de tratamento do que era descartado e nem era sabido que a falta de gestão de resíduos poderia gerar problemas ambientais e sociais). Gerir os resíduos pressupõe tratamento, destinação ambientalmente adequada e, principalmente, prevenção.

Conforme a Política Nacional dos Resíduos Sólidos, destinação final ambientalmente adequada inclui reutilização, reciclagem, compostagem, recuperação e aproveitamento energético, além da disposição final que evite danos à saúde pública, à segurança e impactos ambientais adversos (BRASIL, 2010).

Alió (2008) aponta a necessidade da substituição do modelo finalista, ou seja, da recuperação de materiais, por um modelo de prevenção, já que essa atitude tem o potencial de atingir a raiz de problemas ambientais e sociais.

Todavia, "[...] el proceso de substitución de un modelo por otro no consiste exclusivamente en la substitución tecnológica sino que también comporta cambios sociales, económicos y culturales" (ALIÓ, 2008, s/p). Ou seja, não é só por meio de tecnologias que os problemas relacionados aos resíduos serão reduzidos. É preciso, também, a participação da população envolvida, da administração pública, de empresas e de cidadãos. É preciso que essa participação abranja mudanças de paradigmas para que a percepção de cada indivíduo seja menos influenciada pelo sistema econômico.

Nesse contexto, torna-se importante voltar-se a estudos que possam analisar programas que viabilizem essa mudança de paradigma: do lixo como problema para o lixo como solução. Isto passa pelo reconhecimento do valor do lixo, da sua concepção como pluralidade de materiais de diferentes composições e não somente como uma "massa" de materiais imprestáveis.

Um desses programas foi estabelecido em Umuarama-PR visando tentar resolver problemas distintos, como poluição de rios, geração de renda por meio dos materiais recicláveis e carência nutricional de populações pobres. 
Umuarama é um município de porte populacional médio, com 108.218 habitantes, localizado na mesorregião Noroeste Paranaense, que criou um programa similar ao Câmbio Verde de Curitiba (de troca de alimentos por hortifrutigranjeiros) com o objetivo de resolver o problema de poluição do rio que abastece a cidade. Antes de analisar o programa, é necessário compreender algumas características gerais e os agentes que integram a gestão dos resíduos sólidos no município.

\section{AGENTES DA GESTÃO DOS RESÍDUOS SÓLIDOS URBANOS EM UMUARAMA}

A gestão dos resíduos sólidos de Umuarama-PR é desenvolvida pela administração pública municipal, com a participação de empresas privadas e da Cooperativa dos Trabalhadores e Prestadores de Serviços na Reciclagem de Resíduos Sólidos de Umuarama (Cooperuma), com o apoio da população. Dentre os resíduos de responsabilidade da prefeitura podem-se destacar: resíduos domésticos, comerciais, públicos e de áreas verdes.

Quanto à coleta, ao armazenamento, ao transporte e à destinação final dos resíduos de saúde, resíduos industriais e resíduos oriundos de construção civil "[...] são de responsabilidade dos geradores" (UMUARAMA, 2006).

Para os resíduos sólidos domésticos há a coleta comum ou misturada (matéria orgânica e outros materiais) e a coleta seletiva, ambas efetuadas pela prefeitura. Segundo a administração pública municipal, a coleta misturada acontece três vezes na semana na área urbana e acontece uma vez, aos sábados, nos distritos e vilas rurais. A coleta seletiva de materiais recicláveis ocorre uma vez na semana. Em 2015, foram coletadas 68.639,7 toneladas de resíduos domésticos, 20.136,4 toneladas de resíduos públicos, 2.112 toneladas provenientes da coleta seletiva e 7.460 toneladas de serviços de varrição de ruas (SNIS, 2017).

Os resíduos sólidos produzidos por empresas, comércios e instituições são coletados pela prefeitura até o limite de 120 litros ou 60 quilos por dia. Acima desse volume os estabelecimentos se encaixam na definição de "grande gerador de resíduos", o que transfere a responsabilidade pelo transporte e destinação dos resíduos a esses agentes.

Segundo o Sistema Nacional de Informações sobre Saneamento (2017), Umuarama apresenta 92,83\% da cobertura da coleta de resíduos domiciliares (RDO) com relação à população total e 100\% com relação à população urbana. A coleta seletiva ocorre para $100 \%$ da população urbana.

A cobrança pelos serviços de coleta é feita por meio de taxa específica, de modo que o valor é embutido no IPTU. O valor cobrado varia conforme a metragem do imóvel, e é 
cobrado e atualizado anualmente. Em média, segundo o contador da prefeitura, $R \$ 155,00$ por 100 metros quadrados de imóvel residencial e $R \$ 211,00$ para indústrias e estabelecimentos industriais na mesma metragem, o que é suficiente para suprir as necessidades de coleta, de manutenção do aterro sanitário e pequenos investimentos.

Segundo o responsável pela gestão dos resíduos sólidos de Umuarama-PR, os resíduos de serviço de saúde são coletados e tratados por empresa terceirizada; não há a incineração desse tipo de resíduo dentro do município. Em 2015, foram coletadas 7,8 toneladas de RSS no município (SNIS, 2017).

Resíduos industriais com características similares aos comerciais/domésticos poderão ser recebidos pelo município diretamente no aterro sanitário, sem pagamento de taxa; os demais resíduos são de responsabilidade do gerador que deve providenciar destinação adequada, seja por meio de gerenciamento próprio ou por empresa privada.

Os geradores de resíduos de construção civil devem separar os materiais recicláveis para que sejam coletados seletivamente e manter em caçambas próprias. Em UmuaramaPR é a Cooperativa Ambiental e de Resíduos da Construção Civil - Coopercon (pertencente à cooperativa dos catadores), quem dá destinação a esse tipo de resíduo. O restante dos materiais não recicláveis deve ser destinado ao aterro sanitário.

A Cooperuma (Cooperativa dos Catadores de Umuarama) é responsável pela triagem e preparação dos materiais recicláveis para a comercialização, incluindo aqueles provenientes do Programa Lixo que Vale, que abrange os bairros Jabuticabeiras, Sete Alqueires, Industrial, Arco Iris, Viveiros e Alta da Glória.

Em 2017, o número de catadores cooperados era de 24 pessoas que, segundo integrante da cooperativa, recebem entre $\mathrm{R} \$ 1.000,00$ e 1.200,00 mensais, de acordo com a quantidade vendida e os preços dos materiais no mercado de reciclagem. A Cooperuma recebe, em média, 2.112 toneladas/ano ou 176 toneladas/mês que são provenientes da coleta seletiva efetivada em todo o município de Umuarama-PR, o que perfaz uma taxa de recuperação de resíduos domésticos e similares de apenas 1,43\% (SNIS, 2017).

Segundo o gestor ambiental, há alguns meses haviam 30 cooperados, mas devido à paralisação do Programa Lixo que Vale em 2017-2018, quatro desses cooperados tiveram que ser dispensados, já que não há mais serviço para esse total de trabalhadores.

A prefeitura é a responsável pela coleta dos materiais recicláveis em Umuarama-PR. No entanto, o Programa Lixo que Vale tem como peculiaridade a coleta efetivada por empresa terceirizada contratada por meio de licitação. Essa contratação é mera delegação de execução de atividade, o que não transfere a titularidade da coleta seletiva, que continua sendo da prefeitura. 


\section{PROGRAMA LIXO QUE VALE: CRIAÇÃO E FUNCIONAMENTO}

O Programa Lixo que Vale (PLV) foi criado em 2010 e consiste na troca do resíduo reciclável por moeda verde (moeda fictícia criada para o programa), a qual pode ser usada na compra de alimentos. A utilização da moeda verde acontecia até 2016 exclusivamente em feiras de hortifrutigranjeiros específicas do programa desenvolvidas no Bairro Industrial e no Bairro Jabuticabeiras. As feiras eram abastecidas pelo Banco de Alimentos de Umuarama que adquiria produtos de pequenos agricultores do município. Na reativação do programa em 2018, com a extinção das feiras do PLV, a moeda verde passa a valer para utilização no Sacolão do Produtor, instalação localizada na área central do município e abastecida igualmente por hortifrutigranjeiros produzidos pelos pequenos agricultores locais.

O objetivo inicial do PLV, em 2010, foi de preservar as nascentes do Rio Piava, localizadas no Bairro Jabuticabeiras e Bairro Sete Alqueires, que eram poluídas com o descarte inapropriado de resíduos. O Rio Piava é o rio que abastece a cidade de Umuarama-PR, esse fato contribuiu para que ações de preservação fossem desenvolvidas. Em 2013, o programa foi ampliado, dessa vez com enfoque social, na busca por melhorar a qualidade da alimentação dos moradores dos bairros Industrial, Arco Iris, Viveiros e Alto da Glória, pois apresentavam baixo poder aquisitivo e alimentação precária.

O PLV iniciou-se dentro de uma área de proteção ambiental (APA) que é uma área delimitada e onde a preservação ambiental precisa ser efetiva, pois contempla nascentes, córregos e rios.

De acordo com as informações obtidas em entrevistas com funcionários da prefeitura e moradores, antes das áreas próximas às nascentes do Rio Piava se tornarem APA, já haviam bairros instalados nessa região (além de propriedades rurais como fazendas, sítios e chácaras). Em torno de 110 famílias, que estavam localizadas em áreas onde não havia rede de esgoto, foram removidas para outros bairros da cidade. As outras famílias (que representam, hoje, em torno de 3.500 pessoas) foram mantidas nos bairros.

O problema constatado em Umuarama - PR estava acontecendo na Zona Urbana da APA, onde há a concentração de bairros. Os bairros Jabuticabeiras e Sete Alqueires são bairros próximos às nascentes de vários afluentes do Rio Piava. Com o descarte inadequado dos resíduos, que acontecia nas ruas ou em terrenos baldios, o Rio Piava estava sendo poluído pois, com as chuvas, o lixo era levado ao rio. Isso gerou um problema para a administração pública municipal, já que esse é o rio que abastece toda a cidade de Umuarama-PR.

Com o objetivo de recuperar e preservar as nascentes desse rio criou-se o PLV. A meta inicial era limpar áreas já poluídas, mas para isso era preciso à participação da 
população. Dessa forma, os gestores públicos responsáveis pela criação do PLV relatam que chegaram aos seguintes questionamentos: "Como é que nós vamos mobilizar esse povo? Por que eles vão querer limpar? Só para limpar a água? Não! No máximo eles iam dizer que isso era problema da Sanepar [instituição responsável pelo saneamento básico no município] e eles que limpem. É eles que vão cobrar da gente".

Com esse problema em conseguir mobilizar a população, surgiu a ideia de dar uma contrapartida às famílias que colaborassem. Como se tratava de uma área com poder aquisitivo baixo e alimentação precária decidiu-se por trocar o lixo doméstico reciclável por alimento, e o que supostamente era lixo para as pessoas se tornou uma fonte indireta de renda.

O PLV constitui-se da seguinte forma: os cidadãos armazenam os resíduos recicláveis que produzem (Figura 1); acontece a coleta seletiva desses materiais (Figura 2); no momento da coleta há a pesagem dos resíduos e, conforme o peso e a composição dos materiais, os participantes do PLV recebem moedas verdes (Quadro 1; Figura 3); as moedas verdes podem ser trocadas por alimentos, anteriormente nas feiras do Programa Lixo que Vale e, atualmente, no Sacolão do Produtor (Figura 4). O alimento é escolhido pela pessoa, conforme a necessidade da família, ou seja, não se trata de uma cesta fechada com alimentos específicos e iguais para todos.

Figura 1 - Moradora do Bairro Jabuticabeiras aguardando a coleta dos resíduos recicláveis

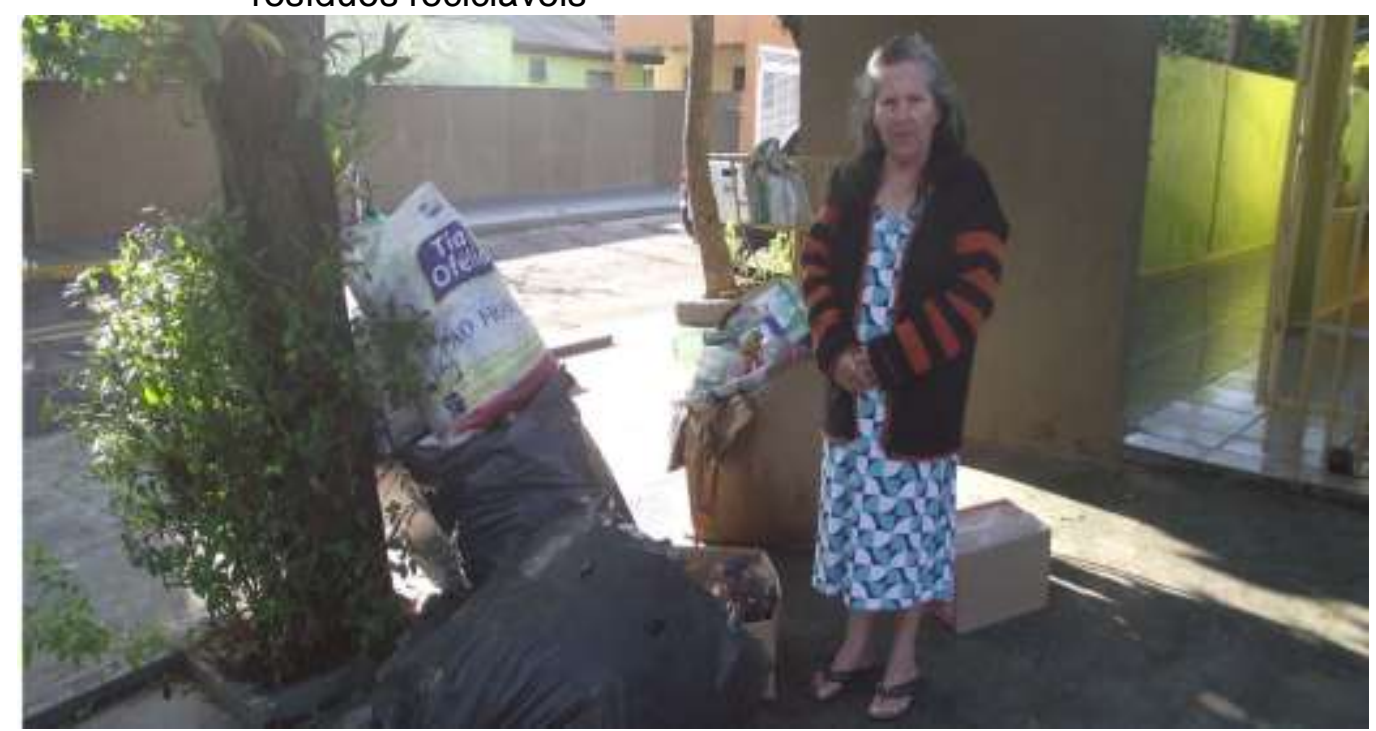

Autoria: Angela D. Kuhn, 2016.

Diante do incentivo em receber alimentos, as pessoas passaram a participar do programa e os resultados, segundo os gestores do programa, começaram a aparecer: reduziu-se a poluição na APA e a contaminação das nascentes do Rio Piava. Em 2013, a administração pública decidiu ampliar o programa, mas dessa vez com enfoque social, para 
contemplar bairros carentes, com problemas de segurança alimentar e nutricional identificados pela prefeitura. Os novos bairros de aplicação do programa foram: Industrial, Arco Iris, Viveiros e Alto da Glória.

Figura 2 - Coleta seletiva do Programa Lixo que Vale

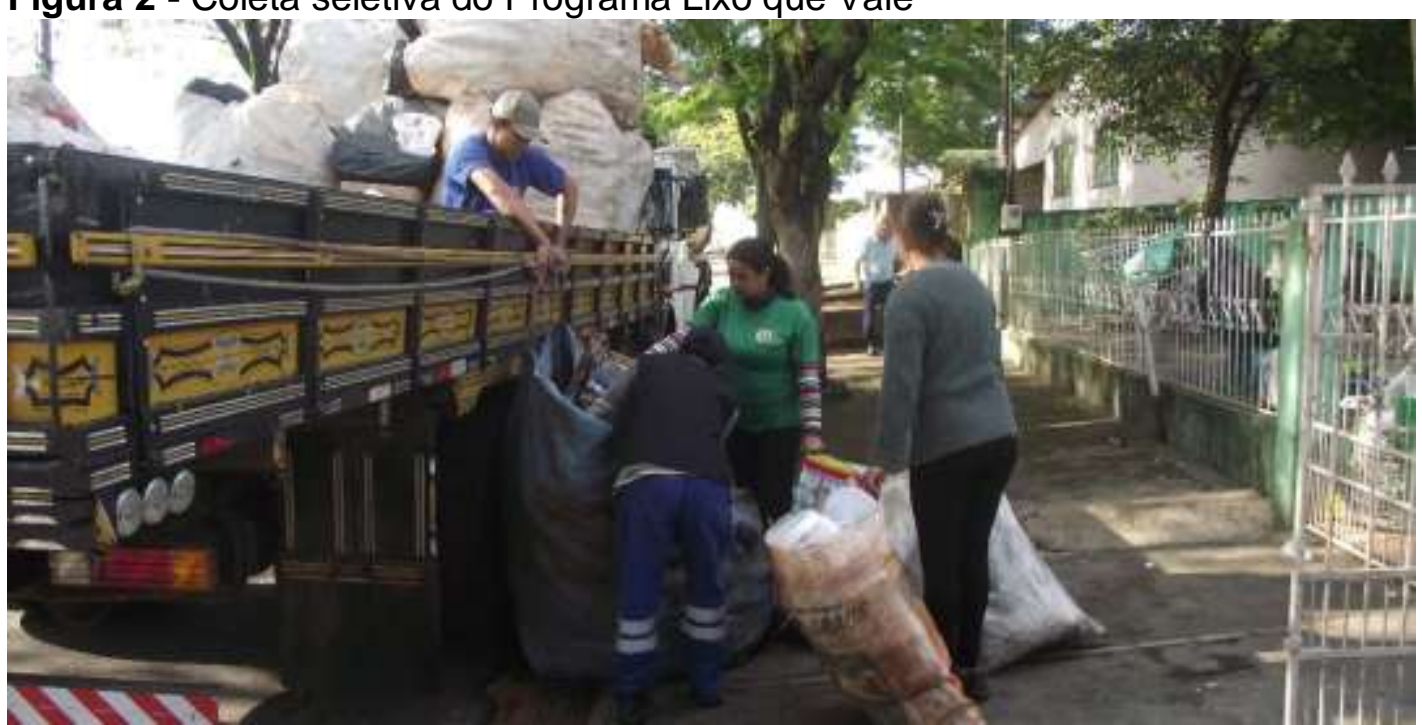

Autoria: Angela D. Kuhn, 2016.

Quadro 1 - Equivalência na troca de resíduos recicláveis pela moeda verde

\begin{tabular}{|l|c|c|}
\hline \multicolumn{1}{|c|}{ Tipo de resíduo reciclável } & Peso $\mathbf{( K g )}$ & Quantidade de moedas verdes \\
\hline Papel e papelão & 1 & 2 \\
\hline Metal & 1 & 8 \\
\hline Sucata, aço, latas de alimentos & 1 & 1 \\
\hline Vidros & 1 & 1 \\
\hline Embalagens plásticas & 1 & 1 \\
\hline & &
\end{tabular}

Fonte: Umuarama (2013)

Figura 3 - Moeda verde do Programa Lixo que Vale

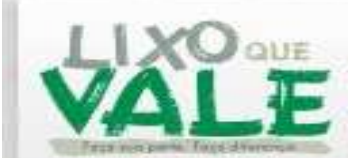

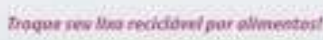

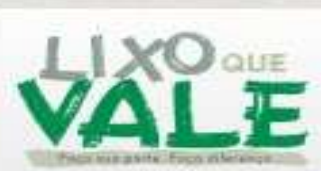

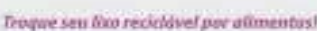
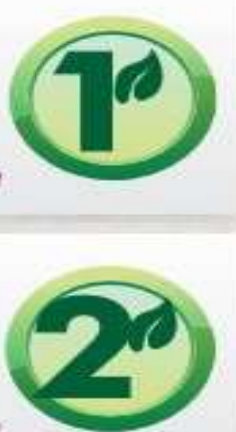

Fonte: Umuarama (2013)

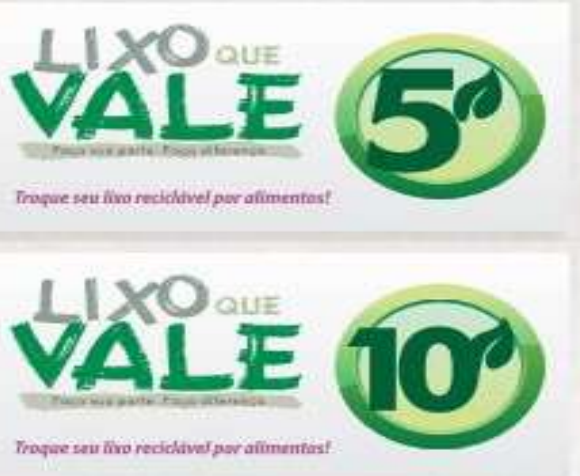

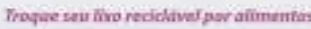

No Programa Lixo que Vale é feito um cadastro por família. Só as famílias cadastradas podem participar da troca da moeda verde por alimentos. Até 2016, havia cerca de 500 
famílias cadastradas entre todos os bairros contemplados. Mas participavam efetivamente da feira em torno de 220 famílias.

Figura 4 - Sacolão do Produtor de Umuarama-PR

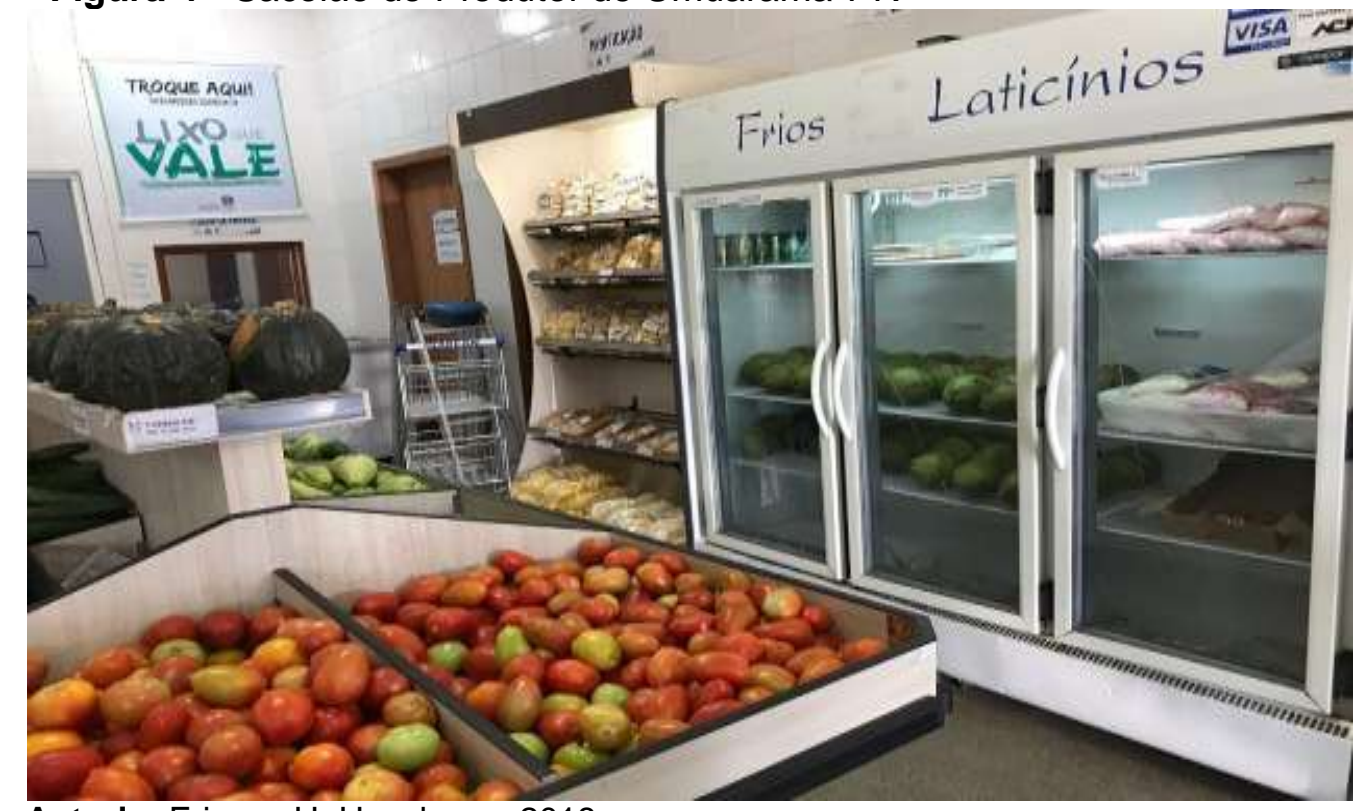

Autoria: Ericson H. Hayakawa, 2018.

O programa contribui para a redução de desperdício de alimentos, pois as moedas verdes são usadas para comprar alimentos que não foram vendidos nas feiras livres e vão para o Sacolão do Produtor, da produção excedente dos agricultores locais ou de programas sociais do Banco de Alimentos.

O programa está espacialmente distribuído em bairros periféricos (Jabuticabeiras, Sete Alqueires, Industrial, Arco Íris, Viveiros e Alto da Glória) que contribuem com 1/3 da quantidade de materiais recicláveis coletados na cidade (Figura 6). Considerando-se que são bairros periféricos, de população majoritariamente pobre, nota-se que a quantidade de resíduos recicláveis do PLV é importante na composição total dos resíduos coletados, mesmo sem considerar a alta qualidade dos materiais do PLV que já são pré-triados pela população. 
Figura 6 - Mapa do fluxo de coleta, destinação e disposição dos resíduos em Umuarama-PR

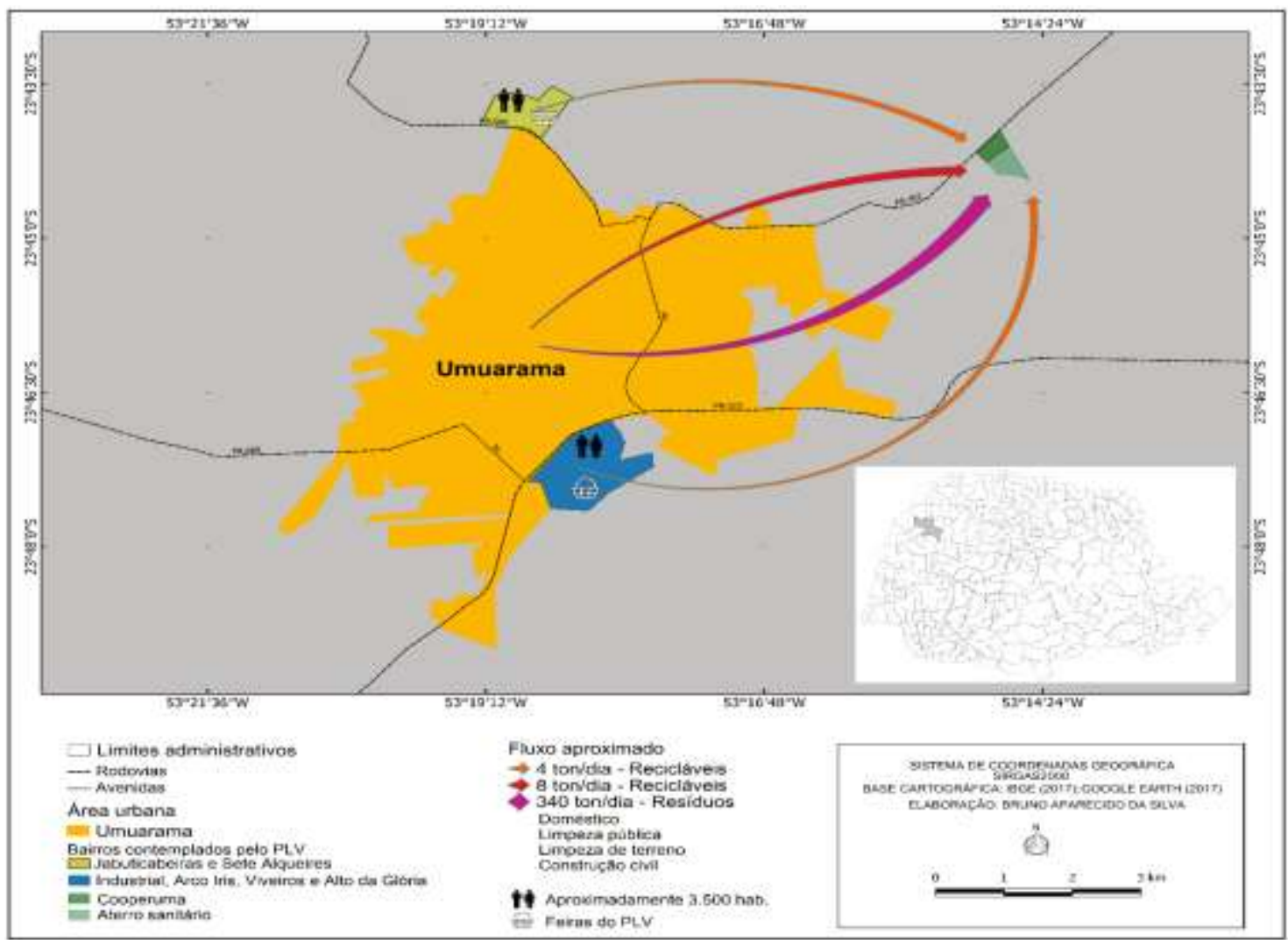

Fonte: IBGE (2017).

\section{PARALIZAÇÃO DO PROGRAMA E SUAS FRAGILIDADES}

No início do ano de 2017, com a nova gestão do município pós-eleições 2016, o PLV foi paralisado. Segundo funcionário municipal entrevistado, a paralisação deveu-se à falta de verba para fazer a licitação da terceirizada que desempenha o trabalho da coleta seletiva nos bairros contemplados pelo programa (o gasto da prefeitura para essa atividade é de $\mathrm{R} \$ 15.000,00$ por mês). Ainda outro motivo apresentado foi o de haver atraso na renovação do convênio com o governo federal para o Programa Compra Direta, o que teria impossibilitado a compra de alimentos para o abastecimento do Banco de Alimentos e, por consequência, teria impedido a realização das feiras do PLV (antes de serem substituídas pelo Sacolão do Produtor).

O convênio foi reestabelecido em meados de 2017 e o PLV não voltou a funcionar neste ano, com o pressuposto de passar por reorganização e reestruturação. Em setembro de 2018 foi anunciada a reativação do programa, com a principal mudança: a extinção das feiras específicas e a aceitação das moedas verdes no Sacolão do Produtor (PREFEITURA..., 2018). 
O período de interrupção do PLV afetou a população contemplada pelo programa, pois depois de seis anos participando, com a troca do resíduo reciclável pela moeda verde e a troca da moeda verde por alimento, essa ação ambiental, social, econômica e nutricional foi paralisada. Durante a interrupção, os catadores entrevistados relataram o enfraquecimento da motivação dos moradores dos bairros-alvo em participar na coleta seletiva, o que fez com que a quantidade de resíduos recicláveis coletados diminuísse. Segundo morador do Bairro Industrial (que também é catador na Cooperuma), ao se referir aos outros moradores do bairro:

Eles falam né: eles pegavam a verdura e agora chega e eles pega o material e dá de graça pra nós ganhar o nosso dinheiro daí eles acham complicado, aí eles guardam. Eles falam, nós ganhava o alimento, tirava a verdura, agora vamos juntar pra pagar funcionário dos outros? (MORADOR DO BAIRRO INDUSTRIAL).

A redução na coleta seletiva foi de quatro a cinco toneladas de resíduos por semana. Isso, por consequência, provocou a dispensa de quatro cooperados da Cooperuma pela redução dos trabalhos. Ocasionou, adicionalmente, a diminuição da renda obtida pelos catadores cooperados e da cooperativa dos pequenos agricultores rurais, já que sem as feiras do Programa Lixo que Vale a demanda pelos produtos rurais diminuiu. Os resultados da reativação recente do programa e do impacto no trabalho dos catadores ainda não podem ser avaliados.

Nas entrevistas realizadas com funcionários da prefeitura e cooperados da Cooperuma e da Cooperu (Cooperativa dos Produtores Rurais de Umuarama), em setembro de 2016, obteve-se a opinião desses agentes sociais quanto ao PLV, com a seguinte indagação: Qual é a sua opinião sobre o Programa Lixo que Vale? O intuito foi de verificar a importância e repercussão desse programa segundo o olhar desses agentes sociais.

Ele é muito abrangente e é um ciclo que fecha e liga tudo, então ele beneficia as pessoas dos bairros; os catadores de recicláveis, que aí gera renda, gera emprego, gera dignidade; melhora a alimentação das pessoas, que é o que mais me comove, por ver as pessoas se alimentando com alimentos mais saudáveis, mais nutritivos (FUNCIONÁRIO DA PREFEITURA).

É muito bom, favorece muito eles, aqui. O material é bom, de primeira. $O$ que vem de lá quase não dá separação porque é pegado nas casas (CATADOR).

Pra mim foi muito bom aparecer esse programa, porque eu não sou obrigada a ter aquela quantia que eles precisam, por exemplo, 100 quilos de alface, se eu não tiver essa quantidade eu posso entregar menos porque não sou só eu, tem mais produtores, também. Então o meu pouco que, às vezes, vai sobrar lá [na feira do pequeno agricultor] eu consigo encaixar [na 
feira do programa Lixo que Vale], e, aí, eu não perco mercadoria, então foi muito bom e, também, aumentou a renda, não é muita coisa, mas é um pouco a mais que aquilo que a gente consegue tirar nas feiras (PEQUENO PRODUTOR RURAL).

Com a expressão das opiniões citadas e a análise do programa como um todo, percebeu-se que o Programa Lixo que Vale se desdobra em resultados que abrangem várias dimensões e diferentes agentes sociais. O programa é visto como provedor de ações que beneficiam o meio ambiente (com a limpeza da APA e do rio Piava), que abrangem questões sociais (geração de emprego e renda a catadores da Cooperuma e aos pequenos produtores rurais; e maior qualidade dos materiais recicláveis obtidos) e envolvem questões relativas à nutrição (melhora na alimentação de famílias carentes.

Durante a interrupção do programa, percebeu-se pelas entrevistas o apelo da população ao seu retorno e a falta do programa para a manutenção da limpeza nos bairros envolvidos: "Faz muita falta o Lixo que Vale, as mulheres cobram da gente que mora lá né?! Elas cobram direto que era a limpeza do bairro aquilo lá né?! Agora tá lá. Antes você não achava um [lixo] no meio da rua, agora você já acha quintal horrível" (catadora). "Tem quintal no Alto da Glória e no Arco Iris que tá cheio [de resíduos recicláveis] eles esperam a volta da feirinha [para trocar a moeda verde]" (morador do bairro Jabuticabeiras).

Além de questões ambientais, questões relativas à nutrição também são destacadas nas entrevistas realizadas com os moradores dos bairros Industrial e Jabuticabeiras. Durante a interrupção do programa, as famílias carentes foram prejudicadas na qualidade da alimentação. Segundo moradores do Bairro Industrial, há pessoas que, por prescrição médica, necessitam consumir alimentos saudáveis (legumes, frutas e verduras), mas que sem o PLV não têm condições financeiras para a compra desses alimentos. Isso coloca em risco a qualidade alimentar e nutricional e fragiliza a saúde das pessoas.

Por fim, para que o Programa Lixo que Vale se mantenha, é necessária a participação da população que corresponde aos bairros Jabuticabeiras, Sete Alqueires, Industrial, Arco Iris, Viveiros e Alto da Glória, para a separação dos resíduos nas residências. É necessária a parceria da Cooperativa de Catadores de Materiais Recicláveis de Umuarama (Cooperuma), para o tratamento e comercialização dos resíduos recicláveis coletados. É importante a parceria da Cooperativa dos Produtores Rurais de Umuarama (Cooperu), para o abastecimento do Banco de Alimentos. É necessária a colaboração da equipe técnica (funcionários da prefeitura e terceirizados da coleta), para a organização do PLV. 


\section{CONSIDERAÇÕES FINAIS}

O Programa Lixo que Vale de Umuarama-PR constitui uma ação em busca da resolução de problemas locais, notadamente em bairros periféricos e com população carente. Foi iniciado por razões ambientais, mas, posteriormente, percebeu-se o seu potencial para a contemplação de outras dimensões. Na dimensão ambiental, há o reaproveitamento de materiais recicláveis; a busca por expandir o período de vida útil do aterro sanitário; e a tentativa de preservar a qualidade da água do rio que abastece a cidade. Na dimensão social, há a contribuição para a melhoria na qualidade da alimentação daqueles que se encontram em situação de risco alimentar. Na dimensão econômica, há a geração de renda aos catadores organizados na Cooperuama e aos pequenos agricultores que abastecem o Banco de Alimentos.

A interrupção do PLV entre 2017-2018 demonstrou algumas fragilidades: a dependência da vontade do gestor municipal em continuar o programa; a dependência do repasse de recursos públicos que vem de fora do programa e até de outras esferas governamentais (recursos federais); e principalmente da sensibilização da população.

A redução do volume de materiais recicláveis coletados durante a interrupção do programa nos bairros que eram contemplados pelo PLV e o necessário esforço para "recriar" hábitos corretos de separação junto à população neste processo de reativação são fundamentais ao programa.

Por fim, concluímos que a percepção dos resíduos como solução de problemas pode beneficiar diretamente distintos agentes sociais (catadores, agricultores e moradores dos bairros selecionados) e indiretamente todo o sistema de gestão municipal de resíduos sólidos. São perceptíveis os benefícios indiretos que atingem a toda a coletividade, pois seus resultados refletem em questões gerais como a preservação ambiental e a saúde pública.

\section{REFERÊNCIAS}

ALIÓ, À. La difícil transición hacia la prevención: una visión desde el análisis de las políticas sobre el reciclaje de residuos urbanos. Revista Electrónica de Geografía y Ciencias Sociales, Barcelona, v. 12, n. 270, 2008. Disponível em: https://www.ub.edu/geocrit/sn/sn270/sn-270-148.htm. Acesso em: 30 set. 2016.

BÖCK, A. Os (des)caminhos da gestão sócio-ambiental no território municipal: a questão dos resíduos sólidos urbanos em Medianeira - PR. 2003. Dissertação (Mestrado em Geografia) - Universidade Federal de Santa Catarina, Florianópolis, 2003.

BRANCO, S. M. O meio ambiente em debate. São Paulo: Moderna, 1999.

BRASIL. Lei $\mathbf{n}^{\circ}$ 12.305, de 02 de agosto de 2010. Institui a Política Nacional de Resíduos Sólidos; altera Lei $n^{\circ} 9.605$ de 12 de fevereiro de 1998; e dá outras providências. Brasília, DF: Presidência da República, 2010. Disponível em: 
http://www.planalto.gov.br/ccivil_03/_ato2007-2010/2010/lei//12305.htm. Acesso: 22 dez. 2016.

CALDERONI, S. Os bilhões perdidos no lixo. São Paulo: Humanistas, 2003.

CARLOS, A. F. A. Diferenciação socioespacial. Revista Cidades, São Paulo, v. 4, n. 6, p. 45-60, 2007.

EIGENHEER, E. M. Lixo, vanitas e morte: considerações de um observador de resíduos. Niterói: EdUFF, 2003.

EIGENHEER, E. M. Lixo: a limpeza urbana através dos tempos. Porto Alegre: Pallotti, 2009. Disponível em: http://www.lixoeeducacao.uerj.br/imagens/pdf/ahistoriadolixo.pdf. Acesso em: 15 ago. 2016.

IBGE. Bases cartográficas. 2017. Disponível em: https://mapas.ibge.gov.br/bases-ereferenciais/bases-cartograficas.html. Acesso em: 2 fev. 2017.

NEVES, F. de O. Gestão pública de resíduos sólidos urbanos: problemática e práticas de gestão no oeste paranaense. 2013. Tese (Doutorado em Geografia) - Universidade Federal do Paraná, Curitiba, 2013.

PREFEITURA anuncia que irá retomar o programa lixo que vale. O Bemdito, Umuarama, 4 set. 2018. Disponível em: http://www.obemdito.com.br/noticias-umuarama/prefeituraanuncia-que-ira-retomar-o-programa-lixo-que-vale/19736/. Acesso em: 5 set. 2018.

SAQUET, M. A. Abordagens e concepções de território. São Paulo: Outras Expressões, 2013.

SNIS - SISTEMA NACIONAL DE INFORMAÇÕES SOBRE SANEAMENTO. Diagnóstico do manejo de resíduos sólidos urbanos: 2017. Disponível em:

http://www.snis.gov.br/diagnostico-residuos-solidos/diagnostico-rs-2017. Acesso em: 20 out. 2018.

UMUARAMA (Município). Lei n 2.971 de 28 de dezembro de 2006. Institui a Lei da Coleta de Umuarama -PR. Umuarama, PR: Câmara Municipal, 2006. Disponível em: http://camaramunicipal-da- umuarama.jusbrasil.com.br/legislacao/525699/lei2971-06. Acesso em: 7 dez. 2016.

UMUARAMA (Município). Projeto lixo que vale. 2013. Disponível em: http://www.umuarama.pr.gov.br. Acesso em: 7 dez. 2016.

Recebido: janeiro de 2019. Aceito: abril de 2019. 